\title{
Purinergic signalling in the subretinal space: a role in the communication between the retina and the RPE
}

\author{
Claire H. Mitchell • David Reigada
}

Received: 10 January 2007 / Accepted: 20 February 2007 / Published online: 14 March 2007

(C) Springer Science + Business Media B.V. 2007

\begin{abstract}
The retinal pigment epithelium (RPE) is separated from the photoreceptor outer segments by the subretinal space. While the actual volume of this space is minimal, the communication that occurs across this microenvironment is important to the visual process, and accumulating evidence suggests the purines ATP and adenosine contribute to this communication. P1 and P2 receptors are localized to membranes on both the photoreceptor outer segments and on the apical membrane of the RPE which border subretinal space. ATP is released across the apical membrane of the RPE into this space in response to various triggers including glutamate and chemical ischemia. This ATP is dephosphorylated into adenosine by a series of ectoenzymes on the RPE apical membrane. Regulation of release and ectoenzyme activity in response to light-sensitive signals can alter the balance of purines in subretinal space, and thus coordinate communication across subretinal space with the visual process.
\end{abstract}

Keywords ATP release $\cdot$ CFTR $\cdot$ Ecto-5'-nucleotidase .

Glutamate $\cdot$ Microenvironment $\cdot$ NTPDase .

Photoreceptors $\cdot$ RPE

\begin{tabular}{|c|c|}
\hline \multicolumn{2}{|c|}{ Abbreviations } \\
\hline $\mathrm{ADP}$ & adenosine diphosphate \\
\hline AMP & adenosine monophosphate \\
\hline ATP & adenosine triphosphate \\
\hline ARL67156 & 6 - $N, N$-diethyl-D- $\beta, \gamma$-dibromomethylene ATP \\
\hline BAPTA & $\begin{array}{l}\text { (1,2-bis(o-aminophenoxy)ethane- } N, N, N^{\prime}, N^{\prime} \text { - } \\
\text { tetraacetic acid) }\end{array}$ \\
\hline
\end{tabular}

C. H. Mitchell $(\bowtie) \cdot$ D. Reigada

Department of Physiology, University of Pennsylvania,

3700 Hamilton Walk, Philadelphia, PA 19104-6085, USA

e-mail: chm@mail.med.upenn.edu

\begin{tabular}{|c|c|}
\hline bFGF & basic fibroblast growth factor \\
\hline CFTR & $\begin{array}{l}\text { cystic fibrosis transmembrane conductance } \\
\text { regulator }\end{array}$ \\
\hline CGS21680 & $\begin{array}{l}\text { (2-[p-(2-carboxyethyl)phenylethylamino]-5'- } \\
N \text {-ethyl-carboxamidoadenosine }\end{array}$ \\
\hline DCKA & 5, 7-dichlorokynurenic acid \\
\hline DMPA & $\begin{array}{l}N(6)-[2-(3,5-\text { dimethoxyphenyl)-2-(2-methyl- } \\
\text { phenyl)-ethyl]adenosine }\end{array}$ \\
\hline EHNA & $\begin{array}{l}\text { erythro-9-(2-hydroxy-3-nonyl)adenine } \\
\text { hydrochloride }\end{array}$ \\
\hline ENPP & $\begin{array}{l}\text { ectonucleotide pyrophosphatase/ } \\
\text { phosphodiesterase }\end{array}$ \\
\hline ERG & electroretinogram \\
\hline GPI & glycosylphosphatidylinositol \\
\hline MK-801 & $\begin{array}{l}(+)-5 \text {-methyl-10,11-dihydro-5H-dibenzo[a,d] } \\
\text { cyclohepten-5,10-imine maleate }\end{array}$ \\
\hline NECA & adenosine-5'-N-ethylcarboxamide \\
\hline NMDA & $N$-methyl-D-aspartic acid \\
\hline NPPB & 5-nitro-2-(3-phenylpropylamino)-benzoate \\
\hline NTPDase & $\begin{array}{l}\text { ectonucleoside triphosphate } \\
\text { diphosphohydrolase }\end{array}$ \\
\hline UDP & uridine diphosphate \\
\hline UTP & uridine triphosphate \\
\hline VEGF & vascular endothelial growth factor \\
\hline
\end{tabular}

\section{Introduction}

The retinal pigment epithelium (RPE) lies between the outer segments of the photoreceptors and the choroidal blood supply (Fig. 1). The RPE combines the functions of epithelial and glial cells, providing a barrier while also supporting the neural photoreceptors and modulating their function. Tight communication between photoreceptors and the RPE is critical to coordinate the multiple levels of 
Fig. 1 Schematic illustration of the key components of purinergic signaling in the subretinal microenvironment. Stimulation of P2 receptors on the RPE can enhance transepithelial fluid absorption while P1 receptors can modulate phagocytosis. ATP released through CFTR and other $\mathrm{Cl}^{-}$ channels can stimulate $\mathrm{P} 2$ receptors or be converted to ADP, AMP, and adenosine (Ado) by a series of ectonucleotidases present on the apical membrane of the RPE. By controlling the balance of extracellular purines available to stimulate these receptors these mechanisms can control levels of endogenous purines available to activate the receptors. While theoretically possible, it remains to be determined whether these subretinal purines can actually stimulate photoreceptors

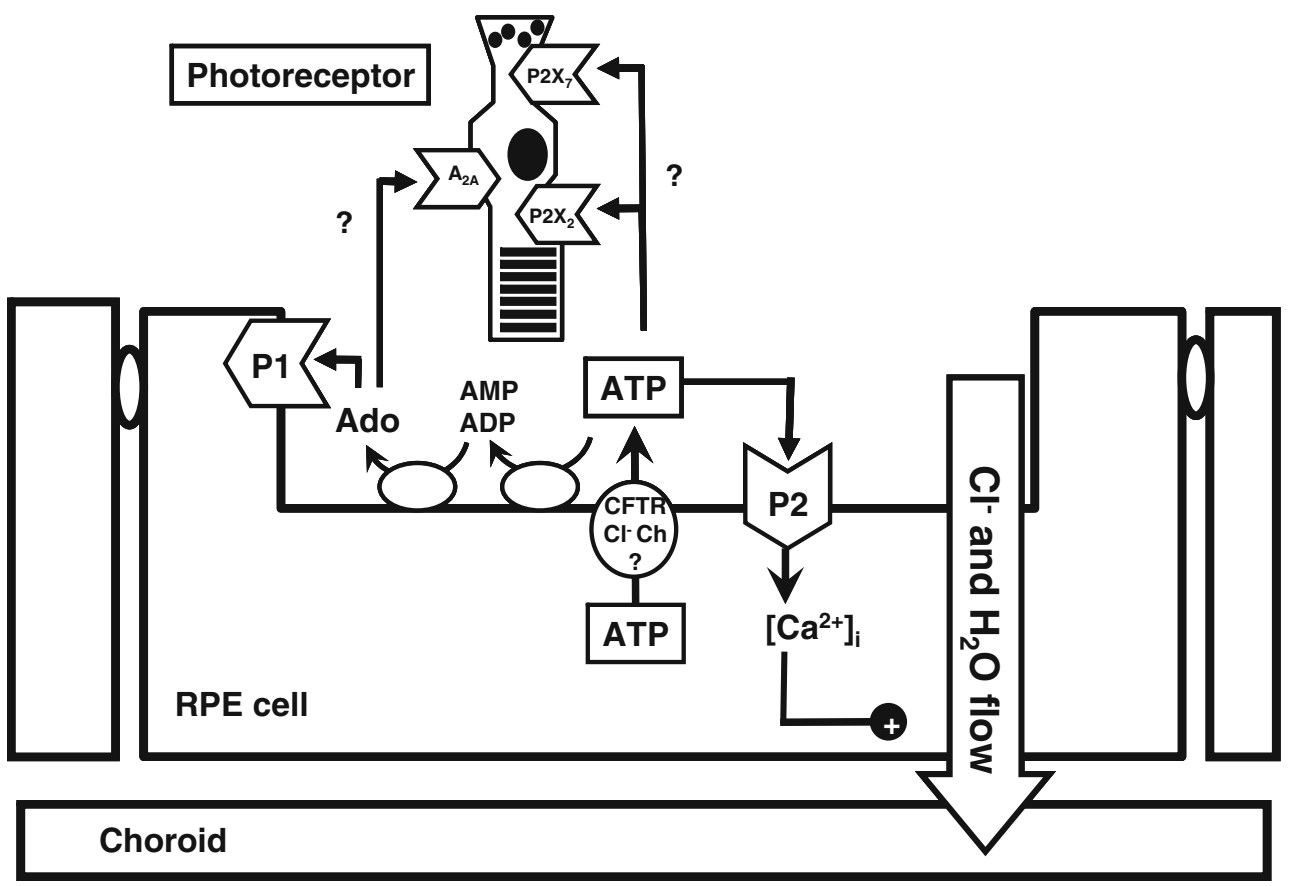

interaction, and the purinergic contribution to this communication is becoming apparent. The relevance of this purinergic input is emphasized by the many functional effects of $\mathrm{P} 1$ and $\mathrm{P} 2$ receptor stimulation and by the multiple mechanisms in place to regulate subretinal levels of purine agonists. As the dynamics of ATP release and extracellular conversion into adenosine will modify agonist availability, the modulation of these processes can exert a temporal control on purinergic signaling. The following review will outline the main interactions between the RPE and photoreceptors, describe the effects of stimulating purinergic receptors on both sides of subretinal space, and summarize how levels of ATP, ADP, and adenosine are manipulated in this microenvironment.

Purines and subretinal space

\section{RPE-photoreceptor interactions across the subretinal space}

The outer segments of the rods and cones are responsible for the initial stages of vision, converting photon energy into a series of enzymatic reactions that close the lightsensitive channels on the photoreceptor plasma membrane, hyperpolarize the cells, and reduce the release of glutamate from the synaptic terminals [1, 2]. Efficient photoreceptor function depends upon both short-term and long-term support from the RPE. The critical nature of these interactions is evident from the rapid degeneration of photoreceptors in the absence of a healthy RPE layer and by the RPE localization of defective gene product in some forms of hereditary photoreceptor degeneration [3].
The apical membrane of the RPE is separated from the plasma membrane of the outer segments by an extracellular space of only 10-20 nm [4]. Although small, this subretinal space contains a highly structured matrix which ensheathes the outer segments and extends to the RPE [5, 6]. The presence of enzymes within this interphotoreceptor matrix emphasizes that this extracellular space itself is functionally active $[7,8]$. This intimate anatomical relationship between photoreceptors and the RPE reflects multiple functional interactions. For example, the RPE accepts, recycles, and exports central components of the phototransduction process [9]. The outer segments are continuously resynthesized, and the phagocytosis, degradation, and processing of shed outer segment tips by the RPE cells is central to this renewal [10]. The ion channels and transporters on the apical membrane of the RPE help regulate the ionic composition of the subretinal space [11]. As extracellular levels of ions can modify the ionic driving forces across the photoreceptor plasma membrane, these RPE transporters can influence the state of neural activity. The transport of fluid and ions from the apical membrane to basolateral membrane of the RPE is also one of the main forces keeping the retina attached [12].

The control of photoreceptor activity by light gives a rapid temporal dependence to some interactions between the photoreceptors and the RPE. The volume of subretinal space increases in response to light [13], linking small changes in the ionic composition of the subretinal space with activity of the RPE transport mechanisms which maintain this volume [14, 15]. Other processes are controlled on a diurnal cycle. The shed tips of the outer 
segments are phagocytosed by the RPE soon after the onset of light $[16,17]$. These processes can both be modulated by purine levels in subretinal space, indicating purinergic regulation is important over multiple time scales.

\section{Purinergic receptors on photoreceptors}

$\mathrm{A}_{2}$ adenosine receptors were localized to both the inner and outer segments of photoreceptor outer segments over a decade ago by Blazynski and colleagues [18], with more recent reports emphasizing their functional role. $\mathrm{A}_{2}$ agonists inhibit the L-type $\mathrm{Ca}^{2+}$ channel on rod outer segments [19] and can inhibit the synaptic release of glutamate from rods, suggesting changes in adenosine levels in subretinal space could modulate light sensitivity [20]. The $\mathrm{A}_{2}$ agonist DPMA and the adenosine deaminase inhibitor EHNA reduce mRNA for opsin in rods, suggesting that endogenous levels of adenosine can downregulate opsin message at night [21]. EHNA and the $\mathrm{A}_{2 \mathrm{~A}}$ receptor agonist CGS21680 also increase the survival of chick embryonic photoreceptors in culture [22], indicating a long-term neuroprotective role for adenosine.

$\mathrm{P} 2$ receptors are also present in the photoreceptors. mRNA for the $\mathrm{P} 2 \mathrm{X}_{2}$ receptor is expressed in the photoreceptor cell bodies, with immunohistochemical localization of the protein to outer segments [23]. In situ hybridization indicates the photoreceptor layer has the highest level of $\mathrm{P}_{2} \mathrm{Y}_{2}$ receptor of any region in the rabbit retina, although staining was not pronounced in monkey [24]. $\mathrm{P} 2 \mathrm{X}_{7}$ receptors have recently been localized to photoreceptor synaptic terminals, with evidence for ecto-ATPase activity in the synapse, and functional evidence suggesting ATP augments transmission of the light response by rods [25]. It was suggested that ATP might be co-released from photoreceptors with glutamate, although this remains to be tested directly.

\section{Purinergic receptors on the RPE}

Stimulation of $\mathrm{P} 1$ receptors can have a considerable impact on RPE cells. $A_{2}$ receptors have been recognized on cultured and fresh RPE cells for some time [26, 27], with in situ hybridization confirming the presence of $\mathrm{A}_{2 \mathrm{~A}}$ receptors in rat RPE [28]. Stimulation of $\mathrm{A}_{2}$ receptors reduces the rate of rod outer segment phagocytosis by RPE cells [29], while application of adenosine to the apical membrane of chick RPE cells increases the basolateral $\mathrm{Cl}^{-}$ conductance, the transepithelial potential, and the c-wave, and decreases the hyperpolarization of the basal membrane in response to light [30]. Although adenosine alone does not increase intracellular $\mathrm{Ca}^{2+}$ levels [31], adenosine acts synergistically with ATP to elevate $\mathrm{Ca}^{2+}$ levels in human RPE cells by stimulating both $\mathrm{A}_{1}$ and $\mathrm{A}_{2 \mathrm{~A}}$ receptors [32, 33]. Stimulation of $A_{1}$ receptors with high doses of NECA increases the active transport of fluorescein across the RPE, while activation of $\mathrm{A}_{2 \mathrm{~A}}$ receptors decreases this transport, and by extension, transport of the ions that underlie fluid movement [34]. Stimulation of $\mathrm{A}_{1}$ and $\mathrm{A}_{2 \mathrm{~A}}$ receptors produces analogous increases and decreases, respectively, in the absorption of subretinal fluid blebs. This is consistent with the negative coupling of the $A_{1}$ receptor and the positive coupling of the $A_{2}$ receptors to adenylate cyclase, as increasing cAMP inhibits the transport of fluid across the RPE towards the choroid [35-37]. The agonist 2-Cl adenosine reverses the deficit in phosphoinositide metabolism found in diabetic RPE cells [38], suggesting effects on metabolism in addition to transport and phagocytosis.

Multiple P2 receptors have been localized to the RPE. The $\mathrm{P} 2 \mathrm{Y}_{2}$ receptor was initially characterized in cultured human RPE [31], with subsequent reports localizing transcript for $\mathrm{P}_{2} \mathrm{Y}_{1}, \mathrm{P}_{2} \mathrm{Y}_{2}, \mathrm{P}_{2} \mathrm{Y}_{4}$, and $\mathrm{P}_{2} \mathrm{Y}_{6}$ in the rat $\mathrm{RPE} /$ choroid [39] and for $\mathrm{P}_{2} \mathrm{Y}_{1}$ and $\mathrm{P}_{2} \mathrm{Y}_{12}$ receptors in ARPE-19 cells [40], and functionally identifying a P2X receptor in rat RPE cells [41]. ATP, ADP, and UTP induce numerous effects on RPE physiology [32, 33, 42, 43]. While these effects likely involve multiple different receptor types, the contributions of the $\mathrm{P}_{2} \mathrm{Y}_{2}$ receptor have been explored in most detail to date. The $\mathrm{P}_{2} \mathrm{Y}_{2}$ receptor has been specifically localized to the apical membrane of fresh bovine RPE cells, and addition of ATP to this membrane transiently elevates $\mathrm{Ca}^{2+}$, activates a basolateral $\mathrm{Cl}^{-}$conductance, inhibits an apical $\mathrm{K}^{+}$conductance, and increases the apical to basolateral flow of fluid [43]. This increased absorption of fluid from the subretinal space suggests $\mathrm{P}_{2} \mathrm{Y}_{2}$ receptor stimulation could reduce the excess fluid that accumulates in retinal edemas, and several reports have supported this theory. ATP, UTP, and the $\mathrm{P}_{2} \mathrm{Y}_{2}$ receptor agonist INS37217 decrease the size of subretinal fluid blebs when injected into subretinal space of rats [44]. In both normal and $\mathrm{rds}+/$ - mice with experimentally induced detachment, INS31217 improves the ERG recovery and decreased cell death [45]. INS37217 also reduces subretinal blebs in rabbits [46]. Injection of another $\mathrm{P}_{2} \mathrm{Y}_{2}$ agonist, INS542, increases the active transport of fluorescein across the RPE, consistent with this upregulation of ion and fluid transport across the tissue [47]. Together these experiments emphasize the clinical potential of treating retinal edema with $\mathrm{P}_{2} \mathrm{Y}_{2}$ agonists.

Regulation of purine levels in subretinal space

While synthesized purinergic agonists may prove useful in treating some ocular disorders, the endogenous activation of $\mathrm{P} 1$ and $\mathrm{P} 2$ receptors in the subretinal microenvironment will ultimately be determined by availability of agonists. These levels are largely controlled by the release of ATP into the subretinal space, its conversion into other purines 
including adenosine, and the manipulation of adenosine by enzymes or transporters. Recent work has increased our understanding of both the stimuli that initiate changes in subretinal purine levels and the mechanisms that mediate these changes.

\section{Release of ATP by the RPE}

At least some of the ATP capable of stimulating the purinergic receptors on RPE cells is released from the RPE itself. The resulting autocrine stimulation ensures local delivery, and control, of purines to initiate the physiologic changes in the RPE. The release of ATP by RPE cells is triggered by multiple stimuli including osmotic stress, bFGF, UTP, NMDA, glutamate, and ATP [39, 40, 48-51]. The ATP release following activation of NMDA receptors by glutamate may have the most interesting implications for communication across subretinal space, given that glutamate confers the light signal from photoreceptors to the rest of the visual system. Glutamate and the specific receptor agonist NMDA triggers ATP release from ARPE-19 cells, with the release inhibited by NMDA antagonist MK-801, and by DCKA, which inhibits the glycine B binding site on NMDA receptors [51, 52]. Although NMDA raises intracellular $\mathrm{Ca}^{2+}$ levels, this increase is prevented by eliminating ATP with apyrase, indicating autostimulation through released ATP is responsible for this $\mathrm{Ca}^{2+}$ signal. NMDA also triggers a release of ATP when applied to the intact bovine RPE eyecup [51]. The NMDA receptors and the ATP release sites have been functionally identified to the apical membrane of the bovine RPE, suggesting the neurotransmitter interactions could amplify the signal from any glutamate reaching subretinal space.

The ability of both UTP and ATP to stimulate release of ATP from the RPE supports the theory that the system acts to amplify signals. When applied at greater than $1 \mu \mathrm{M}$, ATP triggers a secondary release of ATP peaking 10 min after the initial stimuli [40]. UTP also initiates a release in extracellular ATP with a similar delay [48]. The rise in ATP triggered by UTP is inhibited by the $\mathrm{Cl}^{-}$channel blocker NPPB, and UDP is much less effective at triggering release than UTP; both observations suggest the $\mathrm{P}_{2} \mathrm{Y}_{2}$ receptor contributes to the increase in ATP more than diphosphokinase, although influence from the enzyme cannot be ruled out [53].

Recent evidence suggests that ischemia may lead to the release of ATP from RPE cells. Chemical ischemia triggers a substantial ATP release from cardiac myocytes [54], while changes in oxygen levels trigger ATP release in central chemoreceptors [55]. We found that exposure to sodium cyanide led to a rapid release of ATP from ARPE-19 cells (Fig. 2). As hypoxic and/or ischemic challenge may lead to changes in the expression of growth factors in RPE cells during certain ocular disorders such as macular
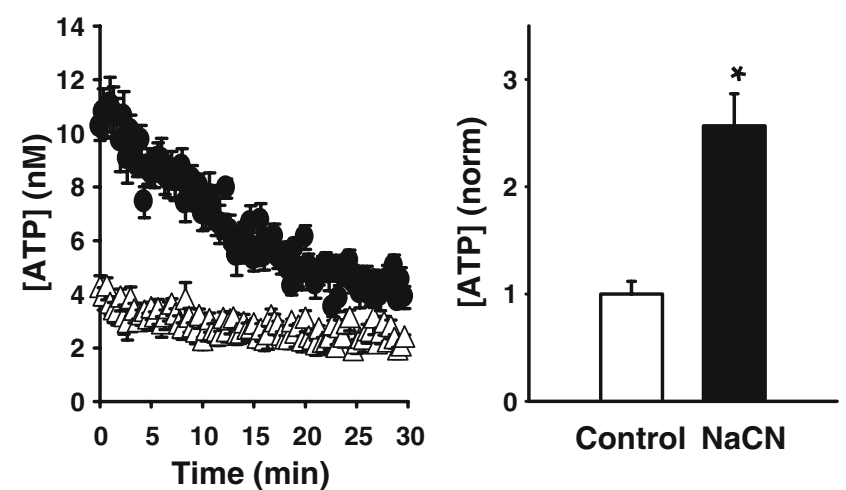

Fig. 2 Chemical ischemia triggers ATP release from ARPE-19 cells. ATP release was measured in the bath directly from cells plated in 96well plates to which the luciferin- luciferase reaction mixture was added [51]. Left Levels of ATP in the bath after addition of $5 \mathrm{mM}$ $\mathrm{NaCN}$ to the cells. Measurement began $1 \mathrm{~min}$ after addition of $\mathrm{NaCN}$ or control solution to wells. Right Levels of ATP measured at the peak, 3 min after addition of $\mathrm{NaCN}(n=12)$. Levels were normalized to concurrent levels in control $(n=14)$. Symbols and bars represent mean $\pm \mathrm{SE},{ }^{*} p<0.001$

degeneration [56], and as purines can induce expression of VEGF in other cells [57], this ATP release may contribute to growth factor signaling by the diseased RPE.

The particular conduit for ATP release varies with the stimuli. The release in response to hypotonic challenge is largely dependent upon CFTR, as it was prevented by the specific CFTR inhibitor CFTR $_{172}$ in addition to the more general blocker glybenclamide [50]. While the precise mechanisms by which CFTR contributes to this release are not yet known, a role for CFTR in ATP release into subretinal space is consistent with the reduction of certain ERG components in cftr -/- mice [58] and with the ability of apical ATP to activate conductances associated with these ERG components [43]. The release of ATP is also largely blocked by the vesicular transport inhibitor brefeldin A, suggesting the two processes occurred in series whereby ATP efflux follows the insertion of vesicles containing CFTR into the plasma membrane. Although the $\mathrm{Ca}^{2+}$ chelator BAPTA blocks this ATP release [50], raising $\mathrm{Ca}^{2+}$ alone with ionophore ionomycin does not itself initiate release [48]. This necessary but not sufficient contribution of $\mathrm{Ca}^{2+}$ also supports a role for vesicular insertion.

In contrast to the release following hypotonic challenge, the ATP release in response to NMDA does not involve CFTR [51]. Release is blocked by NPPB, however, suggesting another type of anion channel could serve as a conduit for ATP release. The presence of parallel mechanisms coexisting on the same cell for ATP release triggered by either agonists or by cell swelling has also been reported in astrocytes [59] and may reflect the multiple roles of purinergic signaling within a given tissue. As both stimuli lead to release across the apical membrane into subretinal 
space, both are expected to influence signaling in the microenvironment.

\section{Interconversion of purines in subretinal space}

The interconversion of nucleotides and nucleosides each capable of stimulating distinct receptors makes the purinergic signaling system of particular interest in a confined region such as the subretinal space. The main enzymes responsible for dephosphorylating extracellular ATP on the RPE cells have been analyzed and a basic understanding of their regulation has begun. This section first describes the enzymes that act on ATP and ADP, followed by enzymes which convert AMP into adenosine.

The dephosphorylation of extracellular ATP by RPE cells involves enzymes from multiple families [40], as found in airway epithelial cells [60]. Degradation of ATP by the apical membrane of the fresh bovine eyecup and by ARPE-19 cells is inhibited by ARL67156 or $\beta \gamma$ mATP. Message for eNPP1, eNPP2, and eNPP3 is present in ARPE-19 cells, consistent with the preference of $\beta \gamma \mathrm{mATP}$ for members of the eNPP family [61]. The cells also express NTPDase2, and NTPDase3, although the intermittent presence of NTPDase1 likely reflects a regulated process [40]. Ecto-alkaline phosphatase has no effect on ATP degradation in RPE cells, in contrast to its considerable contribution in airway epithelium [62]. The putative contribution from diphosphokinases to interconversion of subretinal purines is presently unknown.

Extracellular AMP is rapidly dephosphorylated into adenosine in subretinal space. The production of adenosine from ATP at the apical membrane of the bovine RPE eyecup is inhibited by the ecto-5'-nucleotidase inhibitor $\alpha \beta m A D P$, confirming a role for this enzyme [63]. The enzyme is localized to rat RPE and ARPE-19 cells immunohistochemically. Degradation of 5'AMP is highest near the subretinal space of rat retina [63], although localization in mouse indicated larger amounts of ecto5'-nucleotidase at the tips of adjacent Müller cells [64]. Levamisole does not inhibit the dephosphorylation of $5^{\prime}$ AMP by the RPE, consistent with the absence of substantial ecto-alkaline phosphatase in subretinal space.

The presence of light may alter the levels of adenosine in subretinal space. Epinephrine is released at the onset of light [65] and stimulation of the RPE with epinephrine can decrease activity of ecto-5'-nucleotidase [63]. While norepinephrine and phenylephrine lead to similar decreases in enzyme activity, prazosin and corynanthine block the effects of norepinephrine, implicating the $\alpha 1$ epinephrine receptor in the inhibition of ecto-5'-nucleotidase [63]. The kinetics of inhibition are consistent with cleavage of the nucleotidase from its GPI anchor. The phagocytosis of rod outer segments is maximal shortly after light onset [16], and this phagocytosis is inhibited by adenosine [29]. The ability of epinephrine released by the illuminated retina to reduce ecto-5'-nucleotidase activity and consequently adenosine levels may relieve this inhibition and enhance the rate of phagocytosis at light onset.

Physiologic effects of subretinal purines on the RPE and photoreceptors

The number of purinergic receptors on both photoreceptor and RPE membranes suggests purines make multiple contributions to the physiology of the outer retina. Our increased understanding of how agonist levels in subretinal space are controlled has begun to indicate how and when this contribution may occur. Future research will involve applying these findings from isolated systems to intact RPE-photoreceptor models, and pursuing the role of defective purinergic regulation in ocular disease. While it is unlikely that ATP released across the apical membrane of the RPE can diffuse to these P2 receptors in the outer plexiform layer given the ecto-ATPase activity in the synaptic clef [25], stimulation of receptors elsewhere on the photoreceptor membrane is possible. It would be interesting to determine whether ATP released from the RPE and converted to adenosine by ecto-nucleotidases can actually modulate the response to light by stimulating the $\mathrm{A}_{2 \mathrm{~A}}$ receptors on photoreceptor outer segments. The impact of purinergic signaling on chronic ocular diseases is also of interest, such as the role of ischemia-driven ATP release in VEGF production. While the small size of subretinal space can complicate pharmacologic manipulation within the intact RPE-photoreceptor complex, molecular approaches may provide new insight into how endogenous purines in subretinal space affect the physiology, and pathophysiology, of both RPE and photoreceptors.

Acknowledgements This work was supported by grants EY013434 and EY015537 from the NIH to CHM. The authors would like to thank Wennan Lu and Ji Liu for useful discussions.

\section{References}

1. Lamb TD, Pugh EN Jr (2004) Dark adaptation and the retinoid cycle of vision. Prog Retin Eye Res 23:307-380

2. Schmitz Y, Witkovsky P (1996) Glutamate release by the intact light-responsive photoreceptor layer of the Xenopus retina. J Neurosci Methods 68:55-60

3. Redmond TM, Yu S, Lee E et al (1998) Rpe65 is necessary for production of 11-cis-vitamin A in the retinal visual cycle. Nat Genet 20:344-351

4. Steinberg RH, Wood I (1974) Pigment epithelial cell ensheathment of cone outer segments in the retina of the domestic cat. Proc R Soc Lond B Biol Sci 187:461-478 
5. Hageman GG, Kuehn MH (1998) Biology of the interphotoreceptor matrix-retinal pigment epithelium-retina interface. In: Marmor MF, Wolfensberger TJ (eds) The retinal pigment epithelium. Oxford University Press, New York, pp 361-391

6. Hageman GS, Johnson LV (1987) Chondroitin 6-sulfate glycosaminoglycan is a major constituent of primate cone photoreceptor matrix sheaths. Curr Eye Res 6:639-646

7. Plantner JJ (1992) The presence of neutral metalloproteolytic activity and metalloproteinase inhibitors in the interphotoreceptor matrix. Curr Eye Res 11:91-101

8. Beuckmann CT, Gordon WC, Kanaoka Y et al (1996) Lipocalintype prostaglandin D synthase (beta-trace) is located in pigment epithelial cells of rat retina and accumulates within interphotoreceptor matrix. J Neurosci 16:6119-6124

9. McBee JK, Palczewski K, Baehr W, Pepperberg DR (2001) Confronting complexity: the interlink of phototransduction and retinoid metabolism in the vertebrate retina. Prog Retin Eye Res 20:469-529

10. Young RW, Bok D (1969) Participation of the retinal pigment epithelium in the rod outer segment renewal process. J Cell Biol 42:392-403

11. Hughes BA, Gallemore RP, Miller SS (1998) Transport mechanisms in the retinal pigment epithelium. In: Marmor MF, Wolfensberger TJ (eds) The retinal pigment epithelium. Oxford University Press, New York, pp 103-134

12. Marmor MF (1998) Mechanisms of retinal adhesiveness. In: Marmor MF, Wolfensberger TJ (eds) The retinal pigment epithelium. Oxford University Press, New York, pp 392-405

13. Huang B, Karwoski CJ (1992) Light-evoked expansion of subretinal space volume in the retina of the frog. J Neurosci $12: 4243-4252$

14. Adorante JS, Miller SS (1990) Potassium-dependent volume regulation in retinal pigment epithelium is mediated by $\mathrm{Na}, \mathrm{K}, \mathrm{Cl}$ cotransport. J Gen Physiol 96:1153-1176

15. Bialek S, Miller SS (1994) $\mathrm{K}+$ and $\mathrm{Cl}$ - transport mechanisms in bovine pigment epithelium that could modulate subretinal space volume and composition. J Physiol 475:401-417

16. LaVail MM (1976) Rod outer segment disc shedding in relation to cyclic lighting. Exp Eye Res 23:277-280

17. Bescharse JC, Defoe DM (1998) Role of the retinal pigment epithelium in photoreceptor membrane turnover. In: Marmor MF, Wolfensberger TJ (eds) The retinal pigment epithelium. Oxford University Press, New York, pp 152-174

18. McIntosh HH, Blazynski C (1994) Characterization and localization of adenosine A2 receptors in bovine rod outer segments. J Neurochem 62:992-997

19. Stella SL Jr, Bryson EJ, Thoreson WB (2002) A2 adenosine receptors inhibit calcium influx through L-type calcium channels in rod photoreceptors of the salamander retina. J Neurophysiol $87: 351-360$

20. Stella SL Jr, Bryson EJ, Cadetti L, Thoreson WB (2003) Endogenous adenosine reduces glutamatergic output from rods through activation of A2-like adenosine receptors. J Neurophysiol 90:165-174

21. Alfinito PD, Alli R, Townes-Anderson E (2002) Adenosine A(2a) receptor-mediated inhibition of rod opsin mRNA expression in tiger salamander. J Neurochem 83:665-672

22. Paes-de-Carvalho R, Maia GA, Ferreira JM (2003) Adenosine regulates the survival of avian retinal neurons and photoreceptors in culture. Neurochem Res 28:1583-1590

23. Greenwood D, Yao WP, Housley GD (1997) Expression of the $\mathrm{P} 2 \mathrm{X} 2$ receptor subunit of the ATP-gated ion channel in the retina. Neuroreport 8:1083-1088

24. Cowlen MS, Zhang VZ, Warnock L et al (2003) Localization of ocular P2Y2 receptor gene expression by in situ hybridization. Exp Eye Res 77:77-84
25. Puthussery T, Yee P, Vingrys AJ, Fletcher EL (2006) Evidence for the involvement of purinergic $\mathrm{P} 2 \mathrm{X}$ receptors in outer retinal processing. Eur J Neurosci 24:7-19

26. Blazynski C (1993) Characterization of adenosine A2 receptors in bovine retinal pigment epithelial membranes. Exp Eye Res 56:595-599

27. Friedman Z, Hackett SF, Linden J, Campochiaro PA (1989) Human retinal pigment epithelial cells in culture possess A2adenosine receptors. Brain Res 492:29-35

28. Kvanta A, Seregard S, Sejersen S et al (1997) Localization of adenosine receptor messenger RNAs in the rat eye. Exp Eye Res 65:595-602

29. Gregory CY, Abrams TA, Hall MO (1994) Stimulation of A2 adenosine receptors inhibits the ingestion of photoreceptor outer segments by retinal pigment epithelium. Invest Ophthalmol Vis Sci 35:819-825

30. Maruiwa F, Nao-i N, Nakazaki S, Sawada A (1995) Effects of adenosine on chick retinal pigment epithelium: membrane potentials and light-evoked responses. Curr Eye Res 14:685691

31. Sullivan DM, Erb L, Anglade E et al (1997) Identification and characterization of $\mathrm{P} 2 \mathrm{Y} 2$ nucleotide receptors in human retinal pigment epithelial cells. J Neurosci Res 49:43-52

32. Collison DJ, Tovell VE, Coombes LJ et al (2005) Potentiation of ATP-induced $\mathrm{Ca} 2+$ mobilisation in human retinal pigment epithelial cells. Exp Eye Res 80:465-475

33. Collison DJ et al (2004) Potentiation of ATP-induced calcium responses by adenosine in human RPE cells (abstract). Exp Eye Res 79:110

34. Kawahara A, Hikichi T, Kitaya N et al (2005) Adenosine agonist regulation of outward active transport of fluorescein across retinal pigment epithelium in rabbits. Exp Eye Res 80:493-499

35. Negi A, Marmor MF (1986) Mechanisms of subretinal fluid resorption in the cat eye. Invest Ophthalmol Vis Sci 27:1560-1563

36. Hughes BA, Miller SS, Machen TE (1984) Effects of cyclic AMP on fluid absorption and ion transport across frog retinal pigment epithelium. Measurements in the open-circuit state. J Gen Physiol 83:875-899

37. Miller SS, Hughes BA, Machen TE (1982) Fluid transport across retinal pigment epithelium is inhibited by cyclic AMP. Proc Natl Acad Sci U S A 79:2111-2115

38. Kato K, Thomas TP, Stevens MJ et al (1999) 2-Chloroadenosine reverses hyperglycemia-induced inhibition of phosphoinositide synthesis in cultured human retinal pigment epithelial cells and prevents reduced nerve conduction velocity in diabetic rats. Metab Clin Exp 48:827-833

39. Fries JE, Wheeler-Schilling TH, Guenther E, Kohler K (2004) Expression of P2Y1, P2Y2, P2Y4, and P2Y6 receptor subtypes in the rat retina. Invest Ophthalmol Vis Sci 45:3410-3417

40. Reigada D, Lu W, Zhang X et al (2005) Degradation of extracellular ATP by the retinal pigment epithelium. Am J Physiol Cell Physiol 289:C617-C624

41. Ryan JS, Baldridge WH, Kelly ME (1999) Purinergic regulation of cation conductances and intracellular $\mathrm{Ca} 2+$ in cultured rat retinal pigment epithelial cells. J Physiol 3:745-759

42. Stalmans P, Himpens B (1997) Confocal imaging of Ca2+ signaling in cultured rat retinal pigment epithelial cells during mechanical and pharmacologic stimulation. Invest Ophthalmol Vis Sci 38:176-187

43. Peterson WM, Meggyesy C, Yu K, Miller SS (1997) Extracellular ATP activates calcium signaling, ion, and fluid transport in retinal pigment epithelium. J Neurosci 17:2324-2337

44. Maminishkis A, Jalickee S, Blaug SA et al (2002) The P2Y(2) receptor agonist INS37217 stimulates RPE fluid transport in vitro and retinal reattachment in rat. Invest Ophthalmol Vis Sci 43:3555-3566 
45. Nour M et, Quiambao AB, Peterson WM al (2003) P2Y(2) receptor agonist INS37217 enhances functional recovery after detachment caused by subretinal injection in normal and rds mice. Invest Ophthalmol Vis Sci 44:4505-4514

46. Meyer CH, Hotta K, Peterson WM et al (2002) Effect of INS37217, a P2Y(2) receptor agonist, on experimental retinal detachment and electroretinogram in adult rabbits. Invest Ophthalmol Vis Sci 43:3567-3574

47. Takahashi J, Hikichi T, Mori F et al (2004) Effect of nucleotide P2Y2 receptor agonists on outward active transport of fluorescein across normal blood-retina barrier in rabbit. Exp Eye Res 78:103108

48. Mitchell CH (2001) Release of ATP by a human retinal pigment epithelial cell line: potential for autocrine stimulation through subretinal space. J Physiol 534:193-202

49. Eldred JA, Sanderson J, Wormstone M et al (2003) Stress-induced ATP release from and growth modulation of human lens and retinal pigment epithelial cells. Biochem Soc Trans 31:12131215

50. Reigada D, Mitchell CH (2005) Release of ATP from RPE cells involves both CFTR and vesicular transport. Am J Physiol Cell Physiol 288:C132-C140

51. Reigada D, Lu W, Mitchell C (2006) Glutamate acts at NMDA receptors on fresh bovine and on cultured human retinal pigment epithelial cells to trigger release of ATP. J Physiol 575:707-720

52. Baron BM, Harrison BL, Miller FP et al (1990) Activity of 5,7-dichlorokynurenic acid, a potent antagonist at the N-methylD-aspartate receptor-associated glycine binding site. Mol Pharmacol 38:554-561

53. Lazarowski ER, Homolya L, Boucher RC, Harden TK (1997) Identification of an ecto-nucleoside diphosphokinase and its contribution to interconversion of $\mathrm{P} 2$ receptor agonists. J Biol Chem 272:20402-20407

54. Dutta AK, Sabirov RZ, Uramoto H, Okada Y (2004) Role of ATP-conductive anion channel in ATP release from neonatal rat cardiomyocytes in ischaemic or hypoxic conditions. J Physiol 559:799-812

55. Gourine AV (2005) On the peripheral and central chemoreception and control of breathing: an emerging role of ATP. J Physiol 568:715-724

56. Schlingemann RO (2004) Role of growth factors and the wound healing response in age-related macular degeneration. Graefes Arch Clin Exp Ophthalmol 242:91-101

57. Merighi S, Benini A, Mirandola P et al (2006) Adenosine modulates vascular endothelial growth factor expression via hypoxia-inducible factor-1 in human glioblastoma cells. Biochem Pharmacol 72:19-31

58. Wu J, Marmorstein AD, Peachey NS (2006) Functional abnormalities in the retinal pigment epithelium of CFTR mutant mice. Exp Eye Res 83:424-428

59. Joseph SM, Buchakjian MR, Dubyak GR (2003) Colocalization of ATP release sites and ecto-ATPase activity at the extracellular surface of human astrocytes. J Biol Chem 278:23331-23342

60. Picher M, Boucher RC (2001) Metabolism of extracellular nucleotides in human airways by a multienzyme system. Drug Dev Res 52:66-75

61. Joseph SM, Pifer MA, Przybylski RJ, Dubyak GR (2004) Methylene ATP analogs as modulators of extracellular ATP metabolism and accumulation. Br J Pharmacol 142:1002-1014

62. Picher M, Boucher RC (2000) Biochemical evidence for an ecto alkaline phosphodiesterase I in human airways. Am J Respir Cell Mol Biol 23:255-261

63. Reigada D, Zhang X, Crespo A et al (2006) Stimulation of an a1-adrenergic receptor downregulates ecto-5' nucleotidase activity on the apical membrane of RPE cells. Purinergic Signal 2:499-507

64. Braun N, Brendel P, Zimmermann H (1995) Distribution of $5^{\prime}$ nucleotidase in the developing mouse retina. Brain Res Dev Brain Res 88:79-86

65. Hadjiconstantinou M, Cohen J, Neff NH (1983) Epinephrine: a potential neurotransmitter in retina. J Neurochem 41:1440-1444 